\title{
Quantitative Assessment of Left Ventricular Function During Contrast-Enhanced Dobutamine Stress Echocardiography Predicts Future Cardiac Events in Diabetic Patients
}

\author{
Ryotaro Wake, MD; Masaaki Takeuchi, MD*; \\ Minoru Yoshiyama, MD; Junichi Yoshikawa, MD
}

\begin{abstract}
Background Non-invasive diagnosis and risk stratification of coronary artery disease are important for the selection and optimization of therapeutic interventions in diabetic patients, which may improve survival. The aim of this study was to determine the incremental value of contrast-enhanced dobutamine stress echocardiography (CE-DSE) for risk stratification.

Methods and Results CE-DSE was performed in 326 patients with diabetes mellitus (mean age; $66 \pm 10$ years, 223 men). All patients were followed up for a mean of 29 months (1-61 months). Dobutamine was infused in a standard protocol with an intravenous contrast agent. The primary endpoints for hard cardiac events included cardiac death and nonfatal myocardial infarction. The primary endpoints for total cardiac events included hard cardiac events, unstable angina pectoris, congestive heart failure, and late coronary revascularization ( $>3$ months). Cardiac events occurred in 74 patients. The addition of the CE-DSE results, including abnormal left ventricular end-systolic volume response and left ventricular ejection fraction at peak stress $<50 \%$, to the clinical and rest echocardiography model provided incremental information in predicting total cardiac events (increase in chisquare value for the model from 17 to $24, \mathrm{p}<0.05$ ) and hard cardiac events (increase in chi-square value for the model from 18 to $24, \mathrm{p}<0.05$ ).
\end{abstract}

Conclusions Quantitative assessment of left ventricular function during CE-DSE provides incremental prognostic information in predicting cardiac events in diabetic patients. (Circ J 2006; 70: 868 -874)

Key Words: Contrast agents; Diabetes mellitus; Dobutamine stress echocardiography; Prognosis

D iabetes is a major risk factor for development of coronary artery disease (CAD), which has a high incidence of mortality! ${ }^{-4}$ Identification of diabetic patients at high risk of death or myocardial infarction (MI) is an essential step in planning an appropriate management strategy. Exercise stress testing is the most widely available method for the evaluation of $\mathrm{CAD}^{5-7}$ but exercise capacity is often impaired in diabetic patients, as a result of peripheral vascular disease and neuropathy ${ }^{5-8}$ Dobutamine stress echocardiography (DSE) has been established as a safe and feasible method for the diagnosis of $\mathrm{CAD}^{9-11}$ and the prediction of cardiac events in patients with suspected CAD ${ }^{12-16}$ However, few findings have been obtained regarding the incremental value of DSE in the risk stratification of diabetic patients 5,17 The use of intravenous ultrasound contrast agents during stress echocardiography has been shown to improve diagnostic accuracy in the detection of $\mathrm{CAD} !^{18}$ as well as its prognostic value.$^{19}$ However, no outcome data have been obtained to support the role of contrast-enhanced (CE) DSE in the prediction of cardiac mortality and morbidity in the diabetic population. Thus,

(Received February 24, 2006; revised manuscript received April 10, 2006; accepted April 14, 2006)

Department of Internal Medicine and Cardiology, Graduate School of Medicine, Osaka City University, *Department of Internal Medicine and Cardiology, Tane General Hospital, Osaka, Japan

Mailing address: Masaaki Takeuchi, MD, Department of Internal Medicine and Cardiology, Tane General Hospital, 1-2-31 Sakaigawa, Nishi-ku, Osaka 550-0024, Japan. E-mail: masaaki_takeuchi@ hotmail.com the aim of this study was to examine the incremental value of CE-DSE in the prediction of cardiac events in diabetic patients.

\section{Methods}

\section{Patient Population}

The study cohort consisted of 326 consecutive diabetic patients (25-94 years, mean age: 66 years, 223 men) who had undergone CE-DSE in Tane General Hospital between January 2000 and September 2002. All had type 2 diabetes. The clinical indication for DSE was determination of the presence or severity of myocardial ischemia. Cardiovascular risk factors and clinical status were recorded at the time of DSE. A total of 121 patients had a previous history of MI. Medication was not withheld before DSE. Eighty patients were being treated with $\beta$-adrenergic blockers, 146 with nitrates, 129 with calcium-channel antagonists, 101 with angiotensin-converting enzyme inhibitors, 23 with angiotensin-receptor blockers, 5 with nicorandil, 18 with digitalis, and 43 with diuretics. Informed consent was given by all patients. Hypertension was defined as $\geq 140 \mathrm{mmHg}$ systolic and/or $\geq 90 \mathrm{mmHg}$ diastolic blood pressure on more than one measurement, and/or treatment with antihypertensive medication. Diabetes mellitus was diagnosed as a fasting glucose level of $>126 \mathrm{mg} / \mathrm{dl}$ and/or continuous hypoglycemic treatment. Dyslipidemia was defined as fasting total cholesterol $\geq 220 \mathrm{mg} / \mathrm{dl}$, low density lipoprotein cholesterol $\geq 150 \mathrm{mg} / \mathrm{dl}$, high density lipoprotein cholesterol $<40 \mathrm{mg} / \mathrm{dl}$, and/or treatment with lipid-lowering drugs. 
Table 1 Baseline Clinical Characteristics of Diabetic Patients With and Without Cardiac Events After Contrast-Enhanced Dobutamine Stress Echocardiography

\begin{tabular}{|c|c|c|c|c|c|c|}
\hline & \multicolumn{2}{|c|}{ Total cardiac events } & \multirow[b]{2}{*}{$p$ value } & \multicolumn{2}{|c|}{ Hard cardiac events } & \multirow[b]{2}{*}{$p$ value } \\
\hline & $\begin{array}{c}\text { Without events } \\
n=252\end{array}$ & $\begin{array}{c}\text { With events } \\
\quad n=74\end{array}$ & & $\begin{array}{c}\text { Without events } \\
\quad n=315\end{array}$ & $\begin{array}{c}\text { With events } \\
\quad n=11\end{array}$ & \\
\hline Age $($ mean $\pm S D)$ & $66 \pm 10$ & $66 \pm 9$ & NS & $66 \pm 10$ & $68 \pm 9$ & NS \\
\hline Age $>70$ years $(\%)$ & $87(35)$ & $22(30)$ & NS & $104(33)$ & $5(45)$ & $N S$ \\
\hline Male & $170(67)$ & $53(72)$ & NS & $214(68)$ & $9(82)$ & NS \\
\hline History of $\mathrm{CHF}$ & $23(9)$ & $8(11)$ & NS & $29(9.2)$ & $2(18)$ & $N S$ \\
\hline Previous MI & $82(33)$ & $39(53)$ & $<0.01$ & $117(37)$ & $4(36)$ & $N S$ \\
\hline Smoking & $70(27)$ & $21(28)$ & $N S$ & $87(28)$ & $4(36)$ & $N S$ \\
\hline Hypertension & $192(76)$ & $56(76)$ & NS & $239(76)$ & $9(82)$ & $N S$ \\
\hline Dyslipidemia & $141(56)$ & $47(64)$ & $N S$ & $181(57)$ & $7(64)$ & $N S$ \\
\hline Family history of $C A D$ & 49 (19) & $7(9)$ & $N S$ & $56(18)$ & $0(0)$ & $N S$ \\
\hline$\beta$-blocker & $55(22)$ & $25(34)$ & $<0.05$ & $77(24)$ & $3(27)$ & $N S$ \\
\hline Nitrates & $107(42)$ & $39(53)$ & $N S$ & $144(46)$ & $2(18)$ & $N S$ \\
\hline Ca-channel antagonist & $101(40)$ & $28(38)$ & $N S$ & $125(40)$ & $4(36)$ & $N S$ \\
\hline$A C E I$ & $71(28)$ & $30(41)$ & NS & $95(30)$ & $6(55)$ & $N S$ \\
\hline$A R B$ & $18(7)$ & $5(7)$ & $N S$ & $23(7.3)$ & $0(0)$ & $N S$ \\
\hline Diuretics & $35(14)$ & $8(10)$ & $N S$ & $43(14)$ & $0(0)$ & $N S$ \\
\hline Nicorandil & $5(2)$ & $0(0)$ & NS & $5(1.6)$ & $0(0)$ & $N S$ \\
\hline
\end{tabular}

Compared with diabetic patients without events.

$C H F$, congestive heart failure; $M I$, myocardial infarction; $C A D$, coronary artery disease; ACEI, angiotensin-converting enzyme inhibitor; $A R B$, angiotensin-receptor blocker.

Table 2 CE-DSE Results of Diabetic Patients With and Without Cardiac Events

\begin{tabular}{|c|c|c|c|c|c|c|}
\hline & \multicolumn{2}{|c|}{ Total cardiac events } & \multirow[b]{2}{*}{$p$ value } & \multicolumn{2}{|c|}{ Hard cardiac events } & \multirow[b]{2}{*}{$p$ value } \\
\hline & $\begin{array}{c}\text { Without events } \\
n=252\end{array}$ & $\begin{array}{c}\text { With events } \\
n=74\end{array}$ & & $\begin{array}{c}\text { Without events } \\
n=315\end{array}$ & $\begin{array}{l}\text { With events } \\
\quad n=11\end{array}$ & \\
\hline Positivity on CE-DSE (\%) & $115(46)$ & $43(58)$ & $<0.005$ & $153(49)$ & $5(45)$ & $N S$ \\
\hline WMSI at rest (mean $\pm S D)$ & $1.23 \pm 0.36$ & $1.32 \pm 0.38$ & NS & $1.24 \pm 0.36$ & $1.55 \pm 0.54$ & $<0.05$ \\
\hline WMSI at rest $>1.5$ & $39(15)$ & $19(26)$ & $<0.05$ & $54(17)$ & $4(36)$ & $<0.05$ \\
\hline WMSI at peak stress & $0.72 \pm 0.56$ & $0.99 \pm 0.07$ & $<0.0005$ & $0.76 \pm 0.57$ & $1.38 \pm 0.61$ & $<0.005$ \\
\hline WMSI at peak stress $>1.5$ & $31(12)$ & $16(22)$ & $<0.05$ & $43(14)$ & $4(36)$ & $<0.05$ \\
\hline LVESV at rest & $27 \pm 21$ & $34 \pm 25$ & $<0.05$ & $27 \pm 21$ & $55 \pm 35$ & $<0.005$ \\
\hline LVESV at peak stress & $16 \pm 16$ & $22 \pm 21$ & $<0.05$ & $16 \pm 17$ & $37 \pm 35$ & $<0.005$ \\
\hline LVEDV at rest & $68 \pm 43$ & $73 \pm 27$ & $<0.001$ & $68 \pm 40$ & $94 \pm 35$ & $<0.005$ \\
\hline LVEDV at peak stress & $52 \pm 22$ & $58 \pm 26$ & $N S$ & $53 \pm 22$ & $72 \pm 37$ & $<0.05$ \\
\hline Abnormal LVESV response & $22(9)$ & $13(18)$ & $<0.005$ & $34(11)$ & $1(9)$ & NS \\
\hline LVEF at rest & $63 \pm 15$ & $58 \pm 15$ & $<0.05$ & $62 \pm 15$ & $45 \pm 16$ & $<0.005$ \\
\hline LVEF at rest $<50 \%$ & $39(15)$ & $20(27)$ & $<0.05$ & $54(17)$ & $5(45)$ & $<0.05$ \\
\hline LVEF at peak stress & $73 \pm 15$ & $68 \pm 16$ & $<0.05$ & $73 \pm 15$ & $56 \pm 21$ & $<0.005$ \\
\hline LVEF at peak stress $<50 \%$ & $21(8)$ & $11(15)$ & $N S$ & $28(9)$ & $4(36)$ & $<0.005$ \\
\hline$\%$ predicted max $H R$ & $86 \pm 11$ & $86 \pm 11$ & $N S$ & $86 \pm 11$ & $84 \pm 18$ & $N S$ \\
\hline DP at peak stress & $20,296 \pm 5,082$ & $21,064 \pm 5,093$ & $N S$ & $20,459 \pm 5,030$ & $20,793 \pm 6,822$ & $N S$ \\
\hline
\end{tabular}

Compared with diabetic patients without events.

CE, contrast-enhanced; DSE, dobutamine stress echocardiography; WMSI, wall motion score index; LVESV, left ventricular endsystolic volume; LVEDV, left ventricular end-diastolic volume; LVEF, left ventricular ejection fraction; HR, heart rate; DP, double product.

\section{$C E-D S E$}

Our protocol of CE-DSE is described elsewhere ${ }^{19-22}$ Briefly, parasternal long- and short-axis views of the left ventricle (LV) were digitally acquired at baseline. After obtaining the apical 4-chamber view, $2 \mathrm{ml}$ of the intravenous contrast agent (Levovist, Schering AG, Germany; $300 \mathrm{mg} / \mathrm{ml}$ ) was injected, and CE images were digitally acquired in the apical 4- and 2-chamber views. Dobutamine infusion was started at $5 \mu \mathrm{g} \cdot \mathrm{kg}^{-1} \cdot \mathrm{min}^{-1}$, and increased in 3min stages up to $40 \mu \mathrm{g} \cdot \mathrm{kg}^{-1} \cdot \mathrm{min}^{-1}$. Atropine $(\leq 1 \mathrm{mg})$ was given when required. The same procedure was repeated during 10 and $20 \mu \mathrm{g} \cdot \mathrm{kg}^{-1} \cdot \mathrm{min}^{-1}$ dobutamine infusions and at peak stress to create the quad-screen display. Heart rate and blood pressure were recorded at the end of each stage. Criteria for test termination included (1) attainment of $>85 \%$ of age-predicted maximal heart rate, (2) completion of the stress protocol, and (3) development of obvious wall motion abnormalities. Other reasons for terminating the test were (1) arrhythmias such as ventricular tachycardia or sustained supraventricular tachyarrhythmia and (2) intolerable symptoms.

\section{Echocardiographic Analysis}

A quad-screen format display was created by digitizing the 4 standard imaging planes (non-CE parasternal longand short- axis views and $\mathrm{CE}$ apical 4- and 2-chamber views) at baseline, during low-dose $\left(10 \mu \mathrm{g} \cdot \mathrm{kg}^{-1} \cdot \mathrm{min}^{-1}\right)$ and intermediate dose $\left(20 \mu \mathrm{g} \cdot \mathrm{kg}^{-1} \cdot \mathrm{min}^{-1}\right)$ dobutamine infusions, as well as peak stress. The 4 standard views were also recorded on videotape at the end of each stage. One experienced investigator (M.T.), who was unaware of patient clinical data, performed side-by-side comparison of 
Table 3 Univariate Predictors of Cardiac Events in Diabetic Patients Undergoing CE-DSE

\begin{tabular}{|c|c|c|c|c|c|c|}
\hline & \multicolumn{2}{|c|}{ Total cardiac events } & \multirow{2}{*}{$p$ value } & \multicolumn{2}{|c|}{ Hard cardiac events } & \multirow{2}{*}{$p$ value } \\
\hline & Hazard ratio & $95 \% C I$ & & Hazard ratio & $95 \% C I$ & \\
\hline \multicolumn{7}{|l|}{ Clinical data } \\
\hline Age $>70$ years & 0.88 & - & NS & 2.42 & - & $N S$ \\
\hline Male & 1.2 & - & NS & 4.7 & - & NS \\
\hline Previous MI & 1.89 & $1.19-2.98$ & $<0.01$ & 1.41 & - & NS \\
\hline History of $\mathrm{CHF}$ & 1.21 & - & NS & 3.75 & - & $N S$ \\
\hline \multicolumn{7}{|l|}{ Rest echocardiography data } \\
\hline LVEF at rest $<50 \%$ & 1.82 & $1.09-3.05$ & $<0.05$ & 5.78 & $1.76-18.9$ & $<0.005$ \\
\hline WMSI at rest $>1.5$ & 1.69 & $1-2.85$ & $<0.05$ & 4.02 & $1.23-13.2$ & $<0.05$ \\
\hline \multicolumn{7}{|l|}{ Stress echocardiography data } \\
\hline Positivity on DSE & 1.96 & $1.26-3.12$ & $<0.005$ & 1.18 & - & NS \\
\hline LVEF at peak stress $<50 \%$ & 1.89 & - & $N S$ & 8.92 & $2.71-29.3$ & $<0.0005$ \\
\hline WMSI at peak stress $>1.5$ & 2.01 & $1.16-3.51$ & $<0.05$ & 6.19 & $1.88-20.3$ & $<0.005$ \\
\hline Abnormal LVESV response & 2.52 & $1.38-4.59$ & $<0.005$ & 1.19 & $0.15-9.38$ & $N S$ \\
\hline
\end{tabular}

Compared with diabetic patients without events.

CI, confidence interval. Other abbreviations see in Tables 1,2.

wall motion assessments for each of the 16 segments of the $\mathrm{LV}$, and scored regional wall motion from $0=$ hyperkinesis, $1=$ normal to $4=$ dyskinesis. The wall motion score index (WMSI) was obtained by dividing the sum of individual segment scores by the number of interpretable segments. The result of the test was considered positive for ischemia if stress induced an increase in the wall motion score in one or more segments, with the exception of a change from akinesis to dyskinesis. Wall motion abnormalities that remained unchanged with stress were classified as fixed wall motion abnormalities. Left ventricular end-diastolic volume and end-systolic volume (LVESV) at baseline and peak stress were measured using the modified biplane Simpson's method by one cardiologist (R.W.), and the left ventricular ejection fraction (LVEF) was calculated. The change in LVESV from baseline to peak stress was recorded as normal (decrease in LVESV:LVESV at peak stress-LVESV at baseline $<0$ ) or abnormal (increase in LVESV or absence of decrease: LVESV at peak stressLVESV at baseline $\geq 0$ ) according to previously established criteria!2

\section{Follow-up}

Outcome was determined by patient interview at the outpatient clinic, hospital chart review, and telephone interviews with the patient, close relatives, or referring physician. Endpoints for hard cardiac events included cardiac death and nonfatal MI, whereas total cardiac events included hard cardiac events, congestive heart failure, unstable angina pectoris, and late coronary revascularization. Death was considered cardiac in cases of documented significant arrhythmia and/or cardiac arrest, congestive heart failure, or MI. MI was verified by hospital records using the standard criteria of history, electrocardiography, and cardiac enzyme levels. Because the results of testing would affect the subsequent strategy for coronary revascularization, patients who underwent revascularization within 3 months after CE-DSE were censored, and excluded for the analysis.

\section{Statistical Analysis}

Categorical data are reported as percentages and continuous data as the mean $\pm \mathrm{SD}$. Patient groups were compared by Students' t-test for continuous variables and the chisquare test for categorical variables. Values of $p<0.05$ were considered significant. Cumulative probability of freedom from cardiac events was calculated by the Kaplan-Meier method and compared between groups by the log-rank test. A Cox model was used to compare the strength of associations of cardiac events with several other common clinical variables. In this multivariate analysis, the predictive value of CE-DSE was considered in combination with age, sex, hypertension, tobacco usage, dyslipidemia, previous MI, family history of CAD, diagnosis of CE-DSE, WMSI, change in LVESV, and LVEF on echocardiography. The least significant variables were removed from the model in a backward stepwise manner until only the significant variables remained as independent predictors of cardiac events. To assess the incremental value of CE-DSE data, we calculated the differences in the model likelihood ratio chi-square statistic from that for the overall model with and without CE-DSE variables.

\section{Results}

Clinical findings and CE-DSE results in the overall population are shown by outcome in Tables 1 and 2 . No major complication occurred during CE-DSE. Atropine was given to 203 patients (62\%). Heart rate increased from $70 \pm 12$ to $132 \pm 17$ beats/min $(\mathrm{p}<0.001)$, and systolic blood pressure from $135 \pm 21$ to $156 \pm 35 \mathrm{mmHg}(\mathrm{p}<0.001)$. The mean value of peak heart rate was $86 \pm 11 \%$ of the age-predicted maximum heart rate. One hundred fourteen patients did not reach $>85 \%$ of age-predicted maximal heart rate and of them 54 patients had to cease CE-DSE because of obvious new or worsened wall motion abnormalities. Of the other 60 patients (18\%), 43 ceased the test because of administration of the maximal dose of atropine during $40 \mu \mathrm{g} \cdot \mathrm{kg}^{-1} \cdot \mathrm{min}^{-1}$ dobutamine infusion, 1 had severe chest pain, and 16 for other reasons. Compared with patients who achieved the target heart rate or had obvious wall motion abnormality, a greater percentage of patients with submaximal stress tests were taking $\beta$-blockers $(25 \%$ vs $38 \%$, $\mathrm{p}<0.001$ ). Abnormal CE-DSE results (ischemia or fixed wall motion abnormality) were obtained for 158 patients $(48 \%)$.

\section{Outcomes}

During a mean of 29 months (range 1-61 months) of follow-up, a total of 74 cardiac events occurred, including 11 hard cardiac events (10 cardiac deaths, 1 nonfatal MI), 17 cases of unstable angina, 19 of congestive heart failure, 
Table 4 Multivariate Predictors of Cardiac Events in Diabetic Patients undergoing CE-DSE

\begin{tabular}{|c|c|c|c|c|c|c|}
\hline & \multicolumn{2}{|c|}{ Total cardiac events } & \multirow{2}{*}{$p$ value } & \multicolumn{2}{|c|}{ Hard cardiac events } & \multirow{2}{*}{$p$ value } \\
\hline & Hazard ratio & $95 \% C I$ & & Hazard ratio & $95 \% C I$ & \\
\hline Abnormal LVESV response & 2.52 & $1.36-4.65$ & $<0.05$ & - & - & \\
\hline LVEF at peak stress $<50 \%$ & - & - & & 8.92 & $2.64-30.08$ & $<0.0005$ \\
\hline
\end{tabular}

Compared with diabetic patients without events.

Abbreviations see in Tables 2,3.
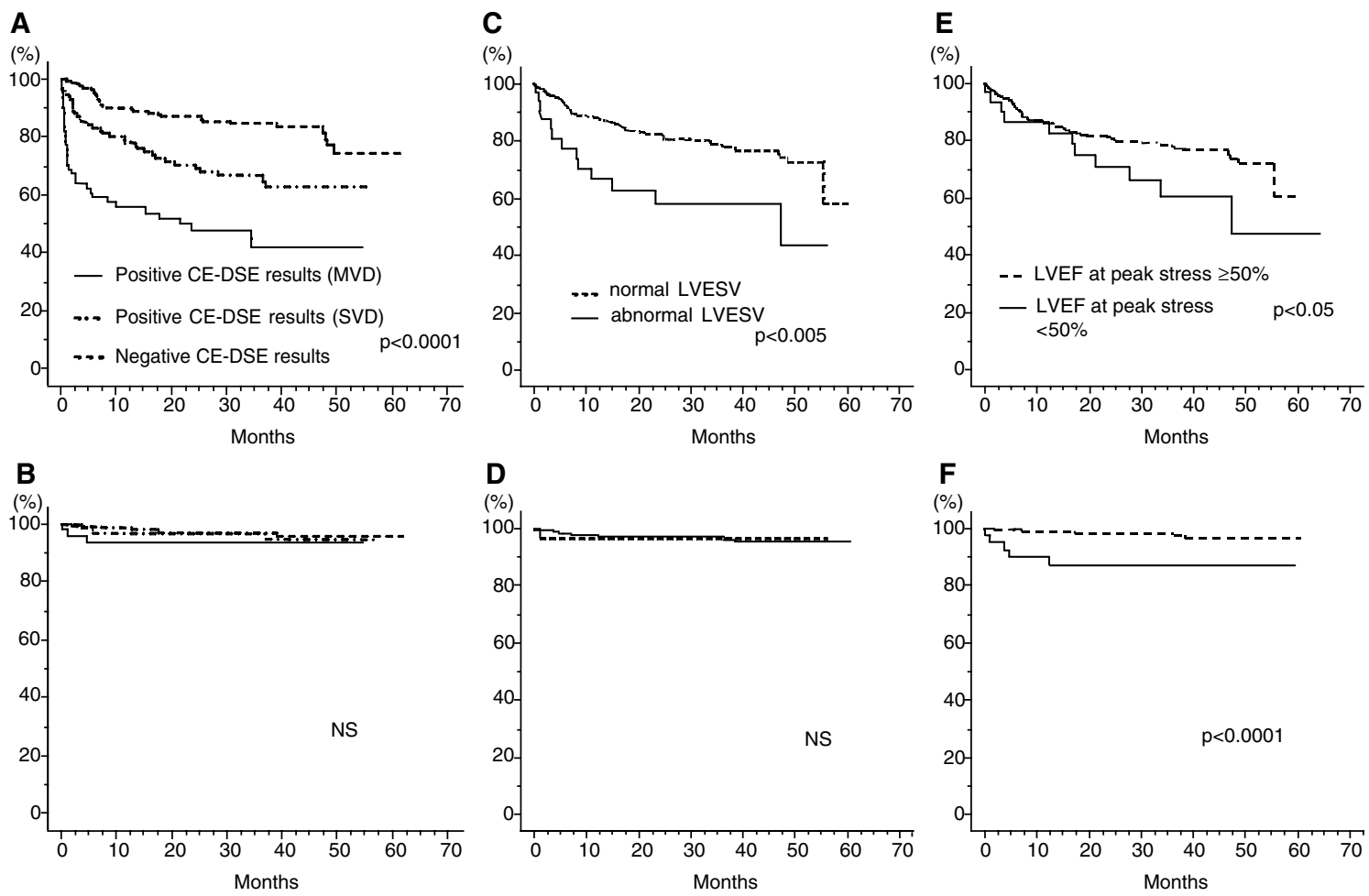

Fig 1. Effect of positive results of contrast-enhanced dobutamine stress echocardiography (CE-DSE) on event-free survival for total cardiac events (A) and hard cardiac events (B). Positive results of CE-DSE in cases of multivessel disease were associated with the lowest event-free survival for total cardiac events. MVD, multivessel disease; SVD, single-vessel disease. Effect of the left ventricular end-systolic volume (LVESV) response during CE-DSE on event-free survival for total cardiac events (C) and hard cardiac events (D). An increase or lack of decrease in LVESV during dobutamine infusion was associated with an increase in total cardiac events. Effect of left ventricular ejection fraction (LVEF) at peak stress during CE-DSE on event-free survival for total cardiac events (E) and hard cardiac events (F). LVEF at peak stress $<50 \%$ was associated with increase in cardiac events.

and 27 late coronary revascularization procedures $(>3$ months from the index CE-DSE). In addition, 23 (7\%) patients underwent early coronary revascularization (coronary angioplasty in 15 patients, coronary bypass grafting in 8 patients) within 3 months of the index CE-DSE, and were censored.

\section{Cox Univariate and Multivariate Analyses}

Univariate predictors of cardiac events are summarized in Table 3. For total cardiac events, history of MI, positive CE-DSE result, LVEF at rest $<50 \%$, an abnormal LVESV response to stress, WMSI at rest $>1.5$, and WMSI at peak stress $>1.5$ were selected as significant predictors by univariate analysis. In a stepwise multivariable model in which all univariate predictors of outcome were considered, the most powerful independent prognostic indicator for total cardiac events was an abnormal LVESV response (Hazard ratio: 2.52, $\mathrm{p}<0.05$ ). For hard cardiac events, univariate analysis showed LVEF at rest $<50 \%$, WMSI at rest
$>1.5, \mathrm{LVEF}$ at peak stress $<50 \%$ and WMSI at peak stress $>1.5$ to be significant predictors. In a stepwise multivariable model in which all univariate predictors of outcome were considered in hard cardiac events, the most powerful independent prognostic indicator of hard cardiac events was LVEF at peak stress $<50 \%$ (Hazard ratio: $8.92, \mathrm{p}<0.0005$ ) (Table 4).

\section{Survival Rate}

Positive CE-DSE results for multivessel disease were associated with the lowest event-free survival rate for total cardiac events (negative: $85.3 \%$, single-vessel disease: $68.2 \%$, multivessel disease: $55.6 \%$ at 3 years, $\mathrm{p}<0.0001$, Fig 1A). However, event-free survival rate for hard cardiac events did not differ significantly among the 3 groups (Fig 1B).

For total cardiac events, event-free survival was significantly lower in diabetic patients with an abnormal LVESV response than in those with a normal LVESV response at 

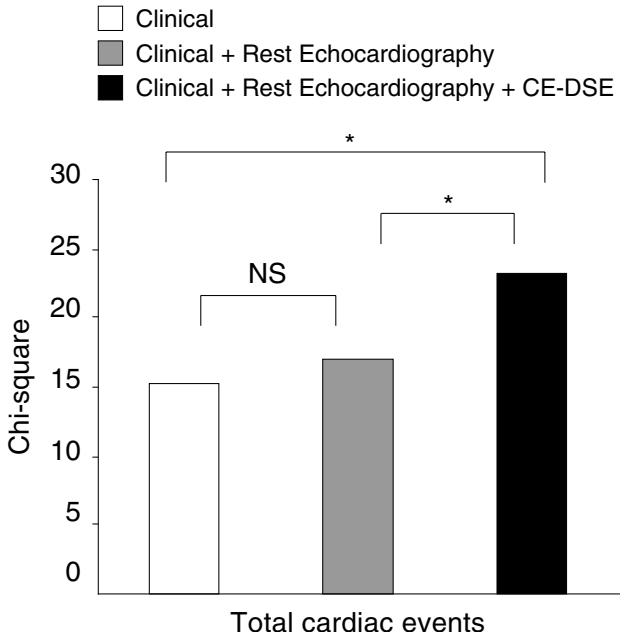

Total cardiac events

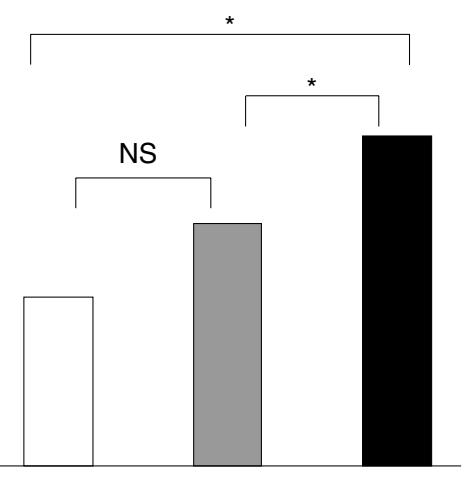

Hard cardiac events
Fig 2. Incremental value of contrast-enhanced dobutamine stress echocardiography (CE-DSE) in predicting total cardiac events (Left) and hard cardiac events (Right). The addition of the imaging variables to the clinical and rest echocardiographic models significantly improved chi-square values. $* \mathrm{p}<0.05$.
3 years $(58.4 \%$ vs $78.3 \%, \mathrm{p}<0.005)$ (Fig 1C). However, the event-free survival rate for hard cardiac events did not differ significantly between the diabetic patients with abnormal and those with normal LVESV responses (Fig 1D). Event-free survival rate was significantly lower for patients with LVEF at peak stress $<50 \%$ than for those with LVEF at peak stress $\geq 50 \%$ (total cardiac events: abnormal $60.3 \%$, normal $77.3 \%$ at 3 years, p<0.05, Fig 1E; Hard cardiac events: abnormal $81.7 \%$, normal $92.6 \%$ at 3 years, $\mathrm{p}<$ 0.0001, Fig 1F).

\section{Incremental Value of CE-DSE}

Fig 2 illustrates the incremental value of CE-DSE in predicting cardiac events. Clinical factors included male sex, previous MI, history of chronic heart failure, age $>70$ years, hypertension, smoking, dyslipidemia, and family history of CAD. The factors for baseline echocardiography consisted of $\mathrm{LVEF}$ at rest $<50 \%$ and WMSI at rest $>1.5$. Because an abnormal LVESV response was selected as a significant predictor for total cardiac events, and LVEF at peak stress $<50 \%$ and WMSI at peak stress $>1.5$ were selected as significant predictors for hard cardiac events by a stepwise model, abnormal CE-DSE results were considered to be abnormal LVESV response and a positive result on CEDSE for total cardiac events and LVEF at peak stress $<50 \%$ and WMSI at peak stress $>1.5$ for hard cardiac events. The addition of CE-DSE abnormalities to the clinical and rest echocardiography model provided incremental information in predicting total cardiac events (increase in chi-square value for the model: from 17 to $24, \mathrm{p}<0.05$ ) and hard cardiac events (increase in chi-square value for the model: from 18 to 24, p<0.05) (Fig 2). The number of patients who showed submaximal stress results with a normal wall motion response was $60(18 \%)$. If we compared these 60 patients with the 108 patients who achieved target heart rate with normal wall motion response, no significant difference of event-free rate was noted between the 2 groups.

\section{Discussion}

This study evaluated the usefulness of CE-DSE in the prediction of cardiac causes of mortality and morbidity in diabetic patients with known or suspected CAD. The independent predictor of total cardiac events was an abnormal LVESV response, and the independent predictor of hard cardiac events was LVEF at peak stress $<50 \%$. These findings suggest that extent of LV dysfunction at peak stress in diabetic patients is the most important independent predictor of cardiac events from the results of CE-DSE.

Although DSE is an established method for diagnosing $\mathrm{CAD}^{11}$ and for risk stratification and determination of prognosis, ${ }^{1-16,23-27}$ its accuracy may be limited by suboptimal endocardial border delineation, which is observed in $10-30 \%$ of unselected patients undergoing stress echocardiography $18,27-29$ Harmonic imaging and intravenous injection of contrast agents have been shown to improve endocardial border delineation, and have enhanced the diagnostic accuracy of DSE 18,27 In this study, we examined the prognostic value of CE-DSE in a particular patient population (ie, diabetic patients at high risk of CAD). In addition to the results as binary criteria (positive and negative), we assessed the prognostic value of additional test variables, including WMSI, change in LVESV, and LVEF. For patients with established CAD, rest LV systolic dysfunction has been found to be a predictor of prognosis. 30 Elhendy et al assessed the value of exercise echocardiography in the prediction of cardiac events in 563 diabetic patients, and found that the extent of both resting LV dysfunction and myocardial ischemia was predictive of cardiac events incremental to clinical data5. Although exercise stress testing is the most physiological stress for induction of myocardial ischemia and provides other useful hemodynamic data, many diabetic patients cannot perform adequate levels of exercise, making CE-DSE a useful alternative for patients with limited exercise capacity.

Among the various dobutamine stress echo variables, an abnormal LVESV response was an independent predictor of total cardiac events. Previous studies have found that an abnormal LVESV response during stress echocardiography is associated with severe $\mathrm{CAD}^{31-33}$ and worse prognosis. ${ }^{12} \mathrm{It}$ is likely that patients with more extensive ischemia induced by dobutamine exhibit an abnormal LVESV response, and thus it is a more important prognostic finding than the binary DSE criteria (positivity on DSE). We demonstrated that an abnormal LVESV response during CE-DSE in diabetic patients provides prognostic information regarding cardiac events.

It is interesting to note that a positive CE-DSE result did not predict hard cardiac events in this study. The most powerful independent prognostic indicator of hard cardiac 
events was LVEF at peak stress $<50 \%$. Although a relatively small number of hard cardiac events made it difficult to conclude a meaningful reason, a negative result for CEDSE does not guarantee the exclusion of future hard events, because the majority of acute coronary events develop from clinically silent coronary lesions. LVEF at peak stress $<50 \%$ might be a composite of resting LV function, contractile reserve and inducible ischemia. These findings demonstrate the importance of resting LV function and the level of severity of myocardial ischemia in predicting hard cardiac events in diabetic patients.

We also demonstrated that abnormal CE-DSE results, including binary criteria, abnormal LVESV response and LVEF at peak stress $<50 \%$, were incremental to clinical and rest echocardiographic variables for predicting adverse long-term outcomes. Our findings again reinforce that in addition to binary criteria, quantitative assessment of LV function during CE-DSE has a pivotal role in accurate prediction of future cardiac events in diabetic population.

There were 60 patients (18\%) who showed submaximal stress results during dobutamine-atropine stress echocardiography in this study. When we compared these 60 patients with the submaximal stress results of 108 patients who achieved the target heart rate with negative ischemia, no significant differences in total and hard cardiac events were noted. These results suggest that with the high dose of dobutamine-atropine stress echocardiography, a submaximal stress result has an equivalent prognostic accuracy when compared with those who achieve the target heart rate with negative stress results.

\section{Study Limitations}

We used a contrast agent for both resting and stress echocardiography of all patients. Thus, we could not determine the incremental value of the addition of a contrast agent over harmonic imaging for predicting future cardiac events. CE images were only acquired in the apical 4- and 2-chamber views, because Levovist is readily destroyed by the ultrasound, and its injection before acquiring parasternal views would produce insufficient LV opacification when acquiring apical views, thus resulting in the underestimation of stress-induced myocardial ischemia, especially in the apex. Medication was not discontinued before CEDSE, so we cannot rule out that it would adversely affect the prognostic value of CE-DSE. The frequency of hard cardiac events appears to be lower in the present study than in previous similar evaluations in Caucasian patients. ${ }^{17} \mathrm{~A}$ possible explanation for this difference is an ethnic factor, because the present study involved only Japanese patients. A recent study showed the prognostic value of myocardial CE echocardiography (MCE) during DSE 34 In the future, it would be desirable to compare the prognostic value of MCE and LV opacification during DSE.

\section{Conclusions}

CE-DSE has an incremental value in identifying diabetic patients at high risk for cardiac events.

\section{References}

1. Grundy SM, Benjamin IJ, Burke GL, Chait A, Eckel RH, Howard $\mathrm{BV}$, et al. Diabetes and cardiovascular disease: A statement for healthcare professionals from the American Heart Association. Circulation 1999; 100: 1134-1146

2. Haffner SM, Lehto S, Ronnemaa T, Pyorala K, Laakso M. Mortality from coronary heart disease in subjects with type 2 diabetes and in nondiabetic subjects with and without prior myocardial infarction. $N$ Engl J Med 1998; 339: 229-234.

3. Kannel WB, McGee DL. Diabetes and cardiovascular risk factors: The Framingham study. Circulation 1979; 59: 8-13.

4. Mak KH, Moliterno DJ, Granger CB, Miller DP, White HD, Wilcox $\mathrm{RG}$, et al. Influence of diabetes mellitus on clinical outcome in the thrombolytic era of acute myocardial infarction: GUSTO-I Investigators (Global Utilization of Streptokinase and Tissue Plasminogen Activator for Occluded Coronary Arteries). J Am Coll Cardiol 1997; 30: $171-179$.

5. Elhendy A, Arruda AM, Mahoney DW, Pellikka PA. Prognostic stratification of diabetic patients by exercise echocardiography. J Am Coll Cardiol 2001; 37: 1551-1557.

6. Ellestad MH, Wan MK. Predictive implications of stress testing: Follow-up of 2700 subjects after maximum treadmill stress testing. Circulation 1975; 51: 363-369.

7. Mark DB, Shaw L, Harrell FE Jr, Hlatky MA, Lee KL, Bengtson JR, et al. Prognostic value of a treadmill exercise score in outpatients with suspected coronary artery disease. $N$ Engl J Med 1991; 325: 849 853.

8. Nesto RW, Phillips RT, Kett KG, Hill T, Perper E, Young E, et al. Angina and exertional myocardial ischemia in diabetic and nondiabetic patients: Assessment by exercise thallium scintigraphy. Ann Intern Med 1988; 108: 170-175.

9. Bates JR, Sawada SG, Segar DS, Spaedy AJ, Petrovic O, Fineberg NS, et al. Evaluation using dobutamine stress echocardiography in patients with insulin-dependent diabetes mellitus before kidney and/or pancreas transplantation. Am J Cardiol 1996; 77: 175-179.

10. Elhendy A, van Domburg RT, Poldermans D, Bax JJ, Nierop PR, Geleijnse ML, et al. Safety and feasibility of dobutamine-atropine stress echocardiography for the diagnosis of coronary artery disease in diabetic patients unable to perform an exercise stress test. Diabetes Care 1998; 21: 1797-1802.

11. Geleijnse ML, Fioretti PM, Roelandt JR. Methodology, feasibility, safety and diagnostic accuracy of dobutamine stress echocardiography. J Am Coll Cardiol 1997; 30: 595-606.

12. Chuah SC, Pellikka PA, Roger VL, McCully RB, Seward JB. Role of dobutamine stress echocardiography in predicting outcome in 860 patients with known or suspected coronary artery disease. Circulation 1998; 97: 1474-1480.

13. Krivokapich J, Child JS, Walter DO, Garfinkel A. Prognostic value of dobutamine stress echocardiography in predicting cardiac events in patients with known or suspected coronary artery disease. $J \mathrm{Am}$ Coll Cardiol 1999; 33: 708-716.

14. Marwick TH, Case C, Sawada S, Rimmerman C, Brenneman P, Kovacs R, et al. Prediction of mortality using dobutamine echocardiography. J Am Coll Cardiol 2001; 37: 754-760.

15. Pingitore A, Picano E, Varga A, Gigli G, Cortigiani L, Previtali M, et al. Prognostic value of pharmacological stress echocardiography in patients with known or suspected coronary artery disease: A prospective, large-scale, multicenter, head-to-head comparison between dipyridamole and dobutamine test (Echo-Persantine International Cooperative (EPIC) and Echo-Dobutamine International Cooperative (EDIC) Study Groups). J Am Coll Cardiol 1999; 34: 17691777.

16. Poldermans D, Fioretti PM, Boersma E, Bax JJ, Thomson IR, Roelandt JR, et al. Long-term prognostic value of dobutamine-atropine stress echocardiography in 1737 patients with known or suspected coronary artery disease: A single-center experience. Circulation 1999; 99: 757-762.

17. Sozzi FB, Elhendy A, Roelandt JR, van Domburg RT, Schinkel AF, Vourvouri EC, et al. Prognostic value of dobutamine stress echocardiography in patients with diabetes. Diabetes Care 2003; 26: $1074-$ 1078

18. Dolan MS, Riad K, El-Shafei A, Puri S, Tamirisa K, Bierig M, et al. Effect of intravenous contrast for left ventricular opacification and border definition on sensitivity and specificity of dobutamine stress echocardiography compared with coronary angiography in technically difficult patients. Am Heart $J$ 2001; 142: 908-915.

19. Wake R, Takeuchi M, Yoshitani H, Miyazaki C, Otani S, Yoshiyama $\mathrm{M}$, et al. Role of contrast-enhanced dobutamine stress echocardiography in predicting outcome in patients with known or suspected coronary artery disease. Echocardiography 2006 (in press).

20. Takeuchi M, Miyazaki C, Yoshitani H, Otani S, Sakamoto K, Yoshikawa J. Assessment of coronary flow velocity with transthoracic Doppler echocardiography during dobutamine stress echocardiography. J Am Coll Cardiol 2001; 38: 117-123.

21. Takeuchi M, Yoshitani H, Miyazaki C, Haruki N, Otani S, Sakamoto $\mathrm{K}$, et al. Color kinesis during contrast-enhanced dobutamine stress 
echocardiography: Feasibility and applicability. Circ J 2003; 67: 49-53.

22. Yoshitani H, Takeuchi M, Hirose M, Miyazaki C, Otani S, Sakamoto $\mathrm{K}$, et al. Head-to-head comparison of fundamental, tissue harmonic and contrast harmonic imaging with or without an air-filled contrast agent, levovist, for endocardial border delineation in patients with poor quality images. Circ J 2002; 66: 494-498.

23. Bigi R, Desideri A, Bax JJ, Galati A, Coletta C, Fiorentini C, et al. Prognostic interaction between viability and residual myocardial ischemia by dobutamine stress echocardiography in patients with acute myocardial infarction and mildly impaired left ventricular function. Am J Cardiol 2001; 87: 283-288.

24. Labib SB, Goldstein M, Kinnunen PM, Schick EC. Cardiac events in patients with negative maximal versus negative submaximal dobutamine echocardiograms undergoing noncardiac surgery: Importance of resting wall motion abnormalities. J Am Coll Cardiol 2004; 44: $82-87$.

25. Poldermans D, Rambaldi R, Fioretti PM, Boersma E, Thomson IR, van Sambeek MR, et al. Prognostic value of dobutamine-atropine stress echocardiography for peri-operative and late cardiac events in patients scheduled for vascular surgery. Eur Heart J 1997; 18(Suppl D): D86-D96.

26. Previtali M, Fetiveau R, Lanzarini L, Cavalotti C, Klersy C. Prognostic value of myocardial viability and ischemia detected by dobutamine stress echocardiography early after acute myocardial infarction treated with thrombolysis. J Am Coll Cardiol 1998; 32: 380-386.

27. Sozzi FB, Poldermans D, Bax JJ, Boersma E, Vletter WB, Elhendy $\mathrm{A}$, et al. Second harmonic imaging improves sensitivity of dobutamine stress echocardiography for the diagnosis of coronary artery disease. Am Heart J 2001; 142: 153-159.

28. Franke A, Hoffmann R, Kuhl HP, Lepper W, Breithardt OA,
Schormann M, et al. Non-contrast second harmonic imaging improves interobserver agreement and accuracy of dobutamine stress echocardiography in patients with impaired image quality. Heart 2000; 83: 133-140.

29. Rainbird AJ, Mulvagh SL, Oh JK, McCully RB, Klarich KW, Shub $\mathrm{C}$, et al. Contrast dobutamine stress echocardiography: Clinical practice assessment in 300 consecutive patients. J Am Soc Echocardiogr 2001; 14: 378-385.

30. Hammermeister KE, DeRouen TA, Dodge HT. Variables predictive of survival in patients with coronary disease: Selection by univariate and multivariate analyses from the clinical, electrocardiographic, exercise, arteriographic, and quantitative angiographic evaluations. Circulation 1979; 59: $421-430$.

31. DePace NL, Iskandrian AS, Hakki AH, Kane SA, Segal BL. Value of left ventricular ejection fraction during exercise in predicting the extent of coronary artery disease. J Am Coll Cardiol 1983; 1: 10021010 .

32. Gibbons RJ, Fyke FE 3rd, Clements IP, Lapeyre AC 3rd, Zinsmeister AR, Brown ML. Noninvasive identification of severe coronary artery disease using exercise radionuclide angiography. $\mathrm{J} \mathrm{Am} \mathrm{Coll} \mathrm{Cardiol}$ 1988; 11: $28-34$

33. Attenhofer CH, Pellikka PA, Oh JK, Roger VL, Sohn DW, Seward JB. Comparison of ischemic response during exercise and dobutamine echocardiography in patients with left main coronary artery disease. J Am Coll Cardiol 1996; 27: 1171-1177.

34. Tsutsui JM, Xie F, O'Leary EL, Elhendy A, Anderson JR, McGrain AC, et al. Diagnostic accuracy and prognostic value of dobutamine stress myocardial contrast echocardiography in patients with suspected acute coronary syndromes. Echocardiography 2005; 22: $487-495$. 